\title{
Cuidados de enfermagem com pacientes submetidos a transplante de células-tronco hematopoiética
}

Nursing care for patients undergoing hematopoietic stem cell transplantation Cuidados de enfermería de pacientes sometidos a trasplante de células madre hematopoyética

Marina IzU ${ }^{1}$ is https://orcid.org/0000-0002-9615-8341

Zenith Rosa Silvino ${ }^{2}$ io https://orcid.org/0000-0002-2848-9747

Lucimere Maria dos Santos ${ }^{1}$ io https://orcid.org/0000-0003-3455-1268 Carlos Marcelo Balbino² io https://orcid.org/0000-0003-0763-3620

Como citar: Izu M, Silvino ZR, Santos LM, Balbino CM. Cuidados de enfermagem com pacientes submetidos a transplante de célulastronco hematopoiética. Acta Paul Enferm. 2021;34: AAPE02892.

DOI

http://dx.doi.org/10.37689/actaape/2021AR02892

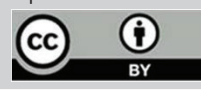

Cuidados de enfermagem; Transplante de célulastronco hematopoiéticas/enfermagem; Transplante

de medula óssea

Keywords

Nursing care; Hematopoietic stem cell transplantation/nursing; Bone marrow

transplantation

Descriptores

Atención de enfermeira; Trasplante de células madre hematopoyéticas/enfermería; Trasplante de

médula ósea

Submetido

12 de Outubro de 2019

Aceito

24 de Junho de 2020

\section{Autor correspondente
Marina lzu}

E-mail: mizu@inca.gov.br

\section{Resumo}

Objetivo: Mapear estudos de enfermagem que contemplem os cuidados de enfermagem com pacientes submetidos ao transplante de células-tronco hematopoiética.

Métodos: Revisão de escopo, cuja busca foi realizada nas bases MEDLINE, CINAHL e LILACS, no período de junho a agosto de 2019, em português, inglês e espanhol. Foram selecionadas 18 publicações que contemplavam a temática.

Resultados: Os cuidados de enfermagem estiveram relacionados às fases do transplante, a saber: condicionamento, infusão, pega e pós-transplante.

Conclusão: 0 conhecimento específico do cuidado de enfermagem com o paciente submetido ao transplante de células-tronco hematopoiética permite ao enfermeiro o reconhecimento de complicações dessa clientela, favorecendo intervenções precoces e visando ao restabelecimento do indivíduo, contribuindo, assim, para uma assistência de enfermagem baseada em evidências.

\section{Abstract}

Objective: To map nursing studies that address nursing care for patients submitted to hematopoietic stem cell transplantation.

Methods: Scoping review, whose search was carried out in the MEDLINE, CINAHL and LILACS bases, from June to August 2019, in Portuguese, English and Spanish. We selected 18 publications on the theme.

Results: The nursing care was related to the phases of the transplantation, namely: conditioning, infusion, harvest, and post-transplantation.

Conclusion: The specific knowledge of nursing care for patients submitted to hematopoietic stem cell transplantation allows the nurse to recognize complications of this clientele, favoring early interventions and aiming to restore the patient, thus contributing to evidence-based nursing care.

\section{Resumen}

Objetivo: Mapear estudios de enfermería que contemplen los cuidados de enfermería de pacientes sometidos al trasplante de células madre hematopoyética.

Métodos: Revisión de alcance, cuya búsqueda fue realizada en las bases MEDLINE, CINAHL y LILACS, en el período de junio a agosto de 2019, en portugués, inglés y español. Fueron seleccionadas 18 publicaciones que contemplaban la temática. 
Resultados: Los cuidados de enfermería estuvieron relacionados con las fases del trasplante, a saber: acondicionamiento, infusión, injerto y postrasplante. Conclusión: El conocimiento específico sobre los cuidados de enfermería de pacientes sometidos al trasplante de células madre hematopoyética permite al enfermero reconocer las complicaciones de esta clientela, favorece intervenciones precoces en busca de la recuperación del individuo y, de esta forma, contribuye para una atención de enfermería basada en evidencias.

\section{Introdução}

O transplante de célula-tronco hematopoiética é utilizado como forma de tratamento em doenças malignas e consiste na infusão intravenosa de células-tronco hematopoiéticas, com a finalidade de reconstituir a função medular e imune de pacientes no tratamento de doenças hematológicas, oncológicas, hereditárias e imunológicas. ${ }^{(1)}$

Como preparo para receber a infusão de células-tronco hematopoiéticas, o paciente recebe quimioterapia e/ou radioterapia, para erradicar sua doença de base, desencadeando a aplasia medular, para reconstituição de uma nova medula. ${ }^{(1-3)}$ Essa terapêutica é composta por quatro fases: condicionamento, infusão, aplasia e recuperação medular. Nesse período, o paciente está constantemente exposto a tecnologias invasivas, procedimentos médicos complexos, e tratamentos que aumentam seu estado de imunossupressão e resistência antimicrobiana. ${ }^{(1,2)}$

Ao realizar o transplante de célula-tronco hematopoiética, a equipe de profissionais precisa atentar para a prevenção e a detecção precoce das principais complicaçóes, que correspondem a infecçóes, doença veno-oclusiva hepática, doença do enxerto contra o hospedeiro, mucosite, náuseas e vômitos, diarreia, alterações hematológicas e complicaçôes pulmonares. ${ }^{(2)}$

Os cuidados de enfermagem ao paciente submetido ao transplante de célula-tronco hematopoiética é complexo e exige nível elevado de competência. O sucesso do transplante é muito influenciado pelo cuidado de enfermagem durante todo o procedimento, cabendo ao enfermeiro individualizar essa tarefa de cuidar, em todas as fases do transplante. ${ }^{(4)}$

São exigidas, da equipe de enfermagem em transplante de célula-tronco hematopoiética, qualificaçôes e experiência técnica, e a assistência de enfermagem deve ser avaliada de forma aprofundada. As atividades de enfermagem precisam ser listadas e analisadas, para se ter claramente seus objetivos e funçóes, e a qualidade do atendimento também pode ser avaliada, com base nas funções desempenhadas. ${ }^{(4)}$

A Sistematização da Assistência de Enfermagem é primordial na otimização e na gerência do cuidado de enfermagem, sendo sua implementação imprescindível na operacionalização do Processo de Enfermagem. ${ }^{(3)}$

Assim, desenvolveu-se o problema de pesquisa com o seguinte questionamento: Quais as características dos cuidados de enfermagem em pacientes submetidos ao transplante de célula-tronco hematopoiética?

O objetivo foi mapear as evidências disponíveis na literatura sobre o cuidado de enfermagem com o transplante de célula-tronco hematopoiética no ambiente hospitalar.

Em estudo bibliométrico sobre as publicaçôes de enfermagem acerca do transplante de célula-tronco hematopoiética, no período de 1997 a 2011, encontrou pouca produção e socialização do conhecimento nessa área. ${ }^{(5,6)}$

\section{Métodos}

Trata-se de pesquisa de abordagem de revisão de escopo (scoping review), que possibilita sintetizar os estudos desenvolvidos e obter conclusóes a partir de um tema de interesse. A revisão de escopo tem como objetivo mapear as evidências existente de um determinado assunto e identificar lacunas na evidência existente, sem analisar a qualidade metodológica dos estudos incluídos, visto que seu objetivo é mapear a evidência científica existente, e não encontrar a melhor evidência. ${ }^{(7,8)}$

Utilizando a estratégia PCC (acrônimo para Participante, Conceito e Contexto), foram incluídos, nesta revisão, estudos em que os participantes fossem transplantados de células-tronco hematopoiética; abordassem o conceito do cuidado de enfermagem nas fases do transplante; no contexto de onco-hematologia, independente da fase do trans- 
plante ou do tipo (autólogo ou alogênico); publicados nos últimos 10 anos (2009-2019). Foram excluídos artigos que trataram da utilização de transplante de células-tronco hematopoiética em doenças autoimune.

Foram seguidos os seis passos metodológicos para a revisão de escopo: identificação da questão de pesquisa; identificação dos estudos relevantes; seleção dos estudos; extração dos dados; separação, sumarização e relatório dos resultados; e divulgação dos resultados. ${ }^{(5,6)}$

A busca pelos artigos foi realizada no período de junho a agosto de 2019, nas bases de dados Literatura Latino-Americana e do Caribe em Ciências da Saúde (LILACS); Medical Literature Analysis and Retrieval System (MEDLINE) e Cumulative Index to Nursing and Allied Health Literature (CINAHL). Realizou-se também a checagem das referências bibliográficas dos estudos selecionados, para localizar o maior número de publicaçóes possível.

A estratégia de busca foi elaborada (Quadro 1) por bibliotecário com experiência e exportada para uma ferramenta de gerenciamento bibliográfico online.

Quadro 1. Estratégia e limitadores da pesquisa, aplicados por base de dados, e os respectivos resultados da pesquisa, por base de dados

\begin{tabular}{|l|l|l|}
\hline Base de dados & Estratégia de busca & $\begin{array}{l}\text { Número de } \\
\text { publicações }\end{array}$ \\
\hline $\begin{array}{l}\text { MEDLINE via } \\
\text { PubMed® }\end{array}$ & $\begin{array}{l}\text { "nursing care"[All Fields] AND "bone marrow } \\
\text { transplantation "[All Fields] AND (("2000/01/01"[PDAT] } \\
\text { :"3000/12/31"[PDAT]) AND (English[lang] OR } \\
\text { Portuguese[lang] OR Spanish[lang])) }\end{array}$ & 16 \\
\hline $\begin{array}{l}\text { CINAHL (via } \\
\text { EBSCO) }\end{array}$ & $\begin{array}{l}\text { "bone marrow transplantation"AND "nursing care" OR } \\
\text { "nursing" }\end{array}$ & 20 \\
\hline LILACS & $\begin{array}{l}\text { "tw:(cuidados de enfermagem AND transplante } \\
\text { de medula ossea) AND (instance:"regional”) AND ( } \\
\text { db:("LILACS") AND type:(“article")) }\end{array}$ & 34 \\
\hline
\end{tabular}

MEDLINE - Medical Literature Analysis and Retrieval System; CINAHL - Cumulative Index to Nursing and Allied Health Literature; EBSCO - Elton B. Stephens Company; LILACS - Literatura Latino-Americana e do Caribe em Ciências da Saúde

Após, separadamente, dois revisores refizeram a busca e leram os artigos selecionados, extraindo os dados e utilizando a matriz de síntese. Para melhor ilustrar, trazemos o diagrama PRISMA com o resumo da busca, na figura 1 .

\section{Resultados}

A análise dos artigos deu-se a partir da leitura crítica e detalhada, extraindo-se os fatores mais rele-

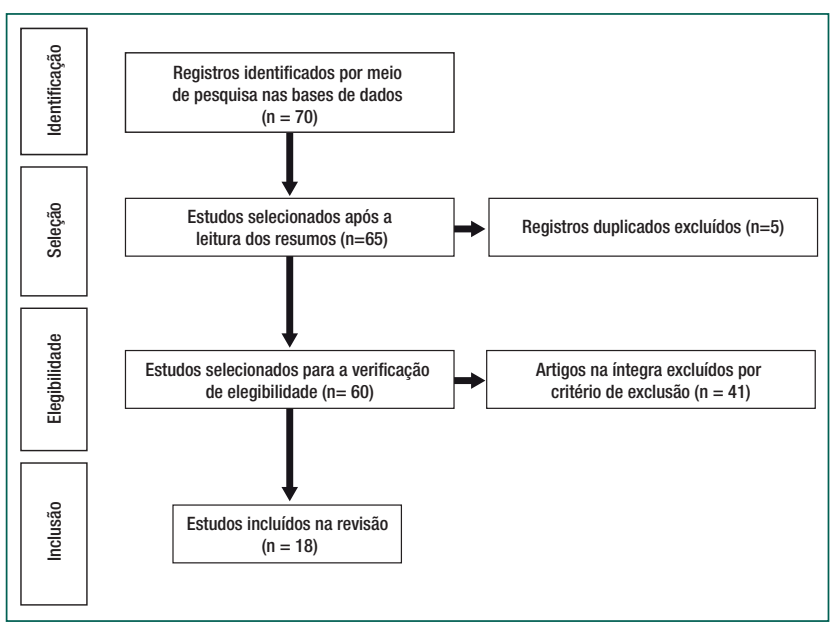

Figura 1. Diagrama de seleção dos estudos conforme 0 Preferred Report Items for Sistematic Reviews and MetaAnalyses (PRISMA)

vantes sobre os cuidados de enfermagem com pacientes submetidos a transplante de células-tronco hematopoiética.

A amostra foi composta por 18 estudos (Quadro 2) que responderam aos critérios de inclusão propostos nesta revisão. Em relação ao ano de publicação, dois foram publicados em 2019, quatro em 2018, três em 2017, dois em 2016, dois em 2015, dois em 2014, um em 2013, um em 2012 e um em 2011. Oito foram publicados em periódicos internacionais e dez em nacionais.

Os cuidados de enfermagem que emergiram da revisão foram classificados de acordo com a fase do transplante: condicionamento, descongelamento das células-tronco e infusão, e com o processo de enfermagem e cuidados especializados, que engloba a prevenção de infecção, cuidados com o cateter venoso central, mucosite e doença enxerto contra hospedeiro são apresentados no quadro 2 .

\section{Discussão}

O restabelecimento do sistema imunológico pode levar vários meses após a infusão das célula-tronco hematopoiética, devido à recuperação lenta dos linfócitos, e, durante este período, os pacientes podem desenvolver complicaçóes. $\mathrm{O}$ enfermeiro deve ter treinamento para prevenir e gerenciar as complicaçôes iniciais e tardias advindas do transplante de 
Quadro 2. Cuidados de enfermagem com pacientes submetidos a transplante de células-tronco hematopoiética

\begin{tabular}{|c|c|}
\hline Cuidados de enfermagem & Artigos \\
\hline $\begin{array}{l}\text { Controle da toxicidade cardiológica, renal, hepática, neurológica e hematológica por conta do condicionamento } \\
\text { Monitorar sinais vitais } \\
\text { Fazer balanço hídrico } \\
\text { Pesar diariamente } \\
\text { Administrar uroprotetores e diuréticos durante infusão de ciclofosfamida (prevenção de cistite hemorrágica) } \\
\text { Mensurar circunferência abdominal diariamente }\end{array}$ & $\begin{array}{l}\text { Lima et al.,(9) Cruz et } \\
\text { al., (10) Figueiredo et al..(11) e } \\
\text { Rodrigues et al. }{ }^{(12)}\end{array}$ \\
\hline $\begin{array}{l}\text { Descongelamento de células-tronco hematopoiética } \\
\text { Usar água destilada estéril no banho-maria para descongelar as células-tronco hematopoiética } \\
\text { Manter a temperatura do banho-maria em } 37^{\circ} \mathrm{C} \\
\text { Tempo máximo de descongelamento de } 5 \text { minutos } \\
\text { Limpar as conexões da bolsa com álcool a } 70 \% \text {, com fricção rigorosa e, no mínimo, três movimentos rotatórios }\end{array}$ & Cruz et al..$^{(10)}$ \\
\hline $\begin{array}{l}\text { Durante a infusão da células-tronco hematopoiética } \\
\text { Colocar carrinho de emergência próximo ao leito do paciente } \\
\text { Administrar anti-histamínico, antiemética, corticosteroide, antipiréticos e diuréticos } 30 \text { minutos antes da infusão } \\
\text { Paramentar-se com avental, máscara e gorro } \\
\text { Calçar luvas estéreis } \\
\text { Colocar o campo estéril fenestrado sob a via que será utilizada } \\
\text { Verificar compatibilidade ABO das células-tronco hematopoiética e do receptor } \\
\text { Fazer flush com solução salina antes e depois da infusão } \\
\text { Infundir células-tronco hematopoiética com equipo para hemocomponentes, sem filtro de leucorredução } \\
\text { Infundir em via exclusiva do cateter } \\
\text { Infundir com tempo máximo de } 10 \text { minutos para cada bolsa } \\
\text { Monitorar sinais vitais durante a infusão } \\
\text { Limpar as conexões com álcool a } 70 \% \\
\text { Atentar para sinais de hipersensibilidade ao dimetilsulfóxido (tremores, tosse, calafrios, febre, vômito, dispneia e edema de glote) } \\
\text { Homogeneizar a bolsa com células-tronco hematopoiética } \\
\text { Monitorizar volume e aspecto da diurese }\end{array}$ & $\begin{array}{l}\text { Cruz et al., (10) Figueiredo et } \\
\text { al. }{ }^{(11)} \mathrm{e} \text { Tormey et al. }{ }^{\left({ }^{(13)}\right.}\end{array}$ \\
\hline $\begin{array}{l}\text { Processo de Enfermagem } \\
\text { Executar o processo (entrevista, exame físico, diagnóstico de enfermagem, prescrição de enfermagem, checagem dos cuidados e registro) } \\
\text { Avaliar desde pré-transplante } \\
\text { Desenvolver planos de cuidados individualizados }\end{array}$ & $\begin{array}{l}\text { Lima et al., } \text { Li) }^{(9)} \text { Rodrigues et } \\
\text { al.,(112) Young et al.(14) e Castro } \\
\text { et al. } .^{(15)}\end{array}$ \\
\hline $\begin{array}{l}\text { Cuidados especializados } \\
\text { Cateter venoso central (cateter de Hickman) } \\
\text { Padronizar os cuidados relativos a inserção, manipulação e manutenção do cateter } \\
\text { Trocar o curativo e fixar o cateter } \\
\text { Manter a permeabilidade do cateter (solução salina heparinizada) } \\
\text { Mensurar a extensão do cateter } \\
\text { Treinar rotineiramente o manuseio do cateter } \\
\text { Prevenir a obstrução trombótica do cateter venoso central }\end{array}$ & 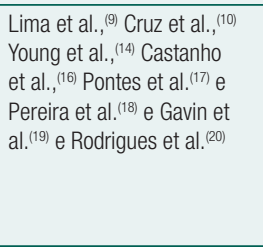 \\
\hline $\begin{array}{l}\text { Prevenção de infecção (isolamento protetor) } \\
\text { Assegurar o uso de máscara facial, quarto com filtro HEPA e rotina de limpeza do quarto } \\
\text { Higiene das mãos antes e depois de entrar no quarto do paciente }\end{array}$ & $\begin{array}{l}\text { Lima et al.,(19) Rodrigues } \\
\text { et al.,.1(1) Biagioli et al. }{ }^{(21)} \mathrm{e} \\
\text { Vokurka et al. }{ }^{(22)} \\
\end{array}$ \\
\hline $\begin{array}{l}\text { Mucosite } \\
\text { Utilizar protocolo padrão de cuidado da cavidade oral } \\
\text { Higienizar os dentes com escova macia } \\
\text { Controlar a dor com administração de analgésicos } \\
\text { Monitoramento do status nutricional }\end{array}$ & $\begin{array}{l}\text { Rodrigues et al. } .^{(12)} \text { e Siefker } \\
\text { et al. } .^{(23)}\end{array}$ \\
\hline $\begin{array}{l}\mathrm{DECH} \\
\text { Conhecer critérios de avaliação de DECH aguda e crônica } \\
\text { Avaliar a pele em busca de erupção cutânea, textura, mobilidade articular } \\
\text { Informar ao paciente cuidados com a pele } \\
\text { Conhecer os efeitos colaterais do tratamento devido ao uso de esteroides (infecção, dano microvascular, disfunção renal e miopatia esteroide) } \\
\text { DECH gastrintestinal }\end{array}$ & $\begin{array}{l}\text { Santos et al. }{ }^{(24)} \text { e Neumann } \\
\text { et al. }{ }^{(25)}\end{array}$ \\
\hline $\begin{array}{l}\text { Educação do paciente e familiar } \\
\text { Orientações na alta hospitalar visando ao autocuidado }\end{array}$ & $\begin{array}{l}\text { Lima et al., }{ }^{(9)} \text { Cruz et al., }{ }^{(10)} \\
\text { Rodrigues et al., } \\
\text { al.(12) Young et } \\
\text { et al. }{ }^{(12)} \text { Castro et al. }{ }^{(15)} \text { Mazza }\end{array}$ \\
\hline Cuidados com a terapia intravenosa (preparar medicações em capela de fluxo laminar) & Lima et al.,(9) Cruz et al.(10) \\
\hline
\end{tabular}

células-tronco hematopoiética, como reaçôes transfusionais, administração segura de medicamentos, prevenção de infecçáo, manejo do cateter venoso central, educação do paciente e familiares, e complicaçóes do regime de condicionamento. ${ }^{(2)}$

O condicionamento é o uso de altas doses de quimioterápico, associado ou não à irradiação corpo- ral total, cuja finalidade é erradicar células malignas residuais, criar um espaço para a enxertia das novas células e induzir a imunossupressão do receptor para diminuir o risco de rejeição do enxerto. ${ }^{(2)}$ Assim, aumenta-se o risco de efeitos colaterais, requerendo cuidados especiais de enfermagem para o controle da toxicidade nos sistemas orgânicos, como controle da 
toxicidade cardiológica, renal, hepática, neurológica e hematológica. ${ }^{(10,11,13,14,16)}$

A hiper-hidratação com diurese forçada durante e até o dia seguinte a administração de agente alquilante é uma das medidas mais efetiva na prevenção de cistite hemorrágica, ${ }^{(2)}$ assim como o uso de uroprotetores e de diuréticos, encurtando o tempo de exposição da bexiga a medicamentos, como a ciclofosfamida, e evitando os efeitos tóxicos.

O Processo de Enfermagem é uma metodologia de trabalho, cientificamente embasada, que norteia o cuidado e sua implementação proporciona assistência individualizada e com excelência, valorizando o trabalho da enfermagem ${ }^{(27)}$ e que aparece em alguns estudos incluídos na revisão. ${ }^{(9,12,14,15)}$

$\mathrm{O}$ uso do cateter venoso central para infusão de célula-tronco hematopoiética evita danos à rede venosa periférica, devido à alta osmolaridade das células-tronco hematopoiéticas criopreservadas, bem como serve para a infusão de grande número de soluçóes (soro, antibióticos e hemoterápicos, e soluçóes hipertônicas) e a coleta de amostras sanguíneas para exames laboratoriais, sendo o cateter de Hickman o pioneiro - usado até os dias atuais. ${ }^{(16,24)}$ Dentre as complicaçóes do cateter de Hickman, estão a arritmia, seu mau posicionamento, a embolia gasosa, o pneumotórax, a hemorragia, a deiscência, a infecção, sua fratura, a embolização e sua migração, justificando os cuidados preconizados. ${ }^{(1,17,19)} \mathrm{A}$ infecção relaciona$\mathrm{da}$ ao cateter venoso central leva ao aumento da mortalidade, bem como do tempo de internação nos primeiros 6 meses após o implante. ${ }^{(18,20,21,23,25)}$

$\mathrm{O}$ uso de via exclusiva para infusão se deve à incompatibilidade das células-tronco hematopoiéticas com outros fluidos e medicamentos (exceto solução salina $0,9 \%$ ), que poderiam danificá-las. ${ }^{(10)}$

O curativo diário do óstio de inserção do cateter permite a inspeção da pele ao redor, em busca de sinais de infecção ou irritação, pela tração e pela fixação do cateter, enquanto a mensuração é parâmetro para identificar sua exteriorização. ${ }^{(11)}$

As células-tronco no transplante autólogo ou do sangue de cordão umbilical estão criopreservadas, e o descongelamento em banho-maria, na temperatura de $37^{\circ} \mathrm{C}$ a $40^{\circ} \mathrm{C}$, garante a viabilidade celular. ${ }^{(10)}$
A administração de medicamentos antes da infusão previne a ocorrência de reaçóes adversas ligadas à presença do dimetilsulfóxido, no caso das células-tronco hematopoiéticas criopreservadas, bem como na vigência de incompatibilidade no sistema $\mathrm{ABO}$ entre receptor e doador. ${ }^{(16,24)}$ Por conta da possibilidade de reação, é necessário que o carrinho de emergência esteja próximo do paciente para atendimento rápido.

A incompatibilidade do sistema $\mathrm{ABO}$ não é motivo de impedimento para a realização do transplante, porém o enfermeiro deve ter este conhecimento antes da infusão, para o planejamento do cuidado do paciente, visto que a incompatibilidade está ligada a reaçôes adversas, como hemólise aguda (no momento ou logo após a infusão) e tardia (5 a 15 dias após a infusão). ${ }^{(16)}$

A infecção é uma das maiores causas de morbidade e mortalidade em pacientes submetidos ao transplante de células-tronco hematopoiética, sendo muito importante uma equipe de enfermagem qualificada, para prevenir, detectar e tratar as infecçóes por meio de precauçóes como higiene das mãos, uso de máscara, luvas, capotes, quartos individuais com filtro..$^{(9,12,21,22)}$

$\mathrm{O}$ uso do filtro high-efficiency particulate air (HEPA) tem como função a prevenção de infecçôes fúngicas, que podem ser letais nesta clientela. ${ }^{(2,22)}$ Pacientes submetidos ao transplante de células-tronco hematopoiética alogênico foram acompanhados por 100 dias pós-transplante, tendo sido observada baixa incidência de pneumonia naqueles em que os quartos dispunham de filtro HEPA. ${ }^{(22)}$

Nos pacientes imunossuprimidos e neutropênicos, a higiene oral para prevenção da mucosite é importante, para prevenir lesóes na barreira mucosa, acarretando infecções, dor, desnutrição e sangramento. ${ }^{(26)}$

Os cuidados de enfermagem incluíram controle de sinais vitais, avaliação da ingesta alimentar, cuidados com cateteres, controle de exames laboratoriais, avaliação do funcionamento dos sistemas corporais, administração de medicamentos e transfusões, medidas de controle de transmissão de microrganismos, educação em saúde/serviço e comunicação integrada com a equipe interdisciplinar. ${ }^{(11,15,22)}$

A educação do paciente e familiar ${ }^{(9,12,14)}$ feita de uma forma claramente compreensível para leigos e 
vinda de uma fonte confiável e consistente entre os prestadores de cuidados pode ser um facilitador no autocuidado de pacientes submetidos TCTH. ${ }^{(28)}$

\section{Conclusão}

O transplante de célula-tronco hematopoiética tem evoluído bastante nas últimas décadas, com o desenvolvimento de técnicas de mobilização e descongelamento de células-tronco hematopoiéticas. Os transplantados são pacientes acometidos por intensos efeitos adversos, causados pelas drogas administradas, e requerem assistência de enfermagem especializada e adequadamente estruturada. O conhecimento específico do cuidado de enfermagem ao paciente submetido ao transplante de célula-tronco hematopoiética permite ao enfermeiro o reconhecimento de complicaçóes nessa clientela, favorecendo intervençóes precoces e visando ao restabelecimento do paciente, além de contribuir para uma assistência de enfermagem baseada em evidências. A atividade de enfermagem no transplante de célula-tronco hematopoiética é complexa e em alto número. $\mathrm{O}$ paciente tem status clínico complexo e dinâmico, e a terapêutica medicamentosa é complexa, em função da toxicidade e dos eventos adversos, requerendo conhecimento do enfermeiro para um cuidado adequado, conforme demonstrado nesta revisão.

\section{Referências}

1. Marques AD, Szczepanik AP, Machado CA, Santos PN, Guimarães PR, Kalinke LP. Hematopoietic stem cell transplantation and quality of life during the first year of treatment. Rev Lat Am Enfermagem. 2018;26(0):e3065.

2. Kenyon M, Babic A, editors. The european blood and marrow transplantation textbook for nurses London: Springer; 2018.

3. Smeltzer S, Bare BG. Brunner e Suddarth: tratado de enfermagem médico-cirúrgica. 12. São Paulo: Guanabara Koogan; 2014.

4. Ferreira M, Nascimento LC, Braga FT, Silva-Rodrigues FM. Competências de enfermeiros nos cuidados críticos de crianças submetidas a transplante de células-tronco hematopoéticas. Rev Eletrôn Enferm. 2017;19:a29.

5. Mercês NN, Erdmann AL. Enfermagem em transplante de células tronco hematopoéticas: produção científica de 1997 a 2007. Acta Paul Enferm. 2010;23(2):271-7.
6. Lima K, Bernardino E, Wolff L, Peres A. Características da produção científica de enfermagem acerca de transplante de células-tronco hematopoiéticas. Cogitare Enferm. 2012;17(3):568-73.

7. Peters MD, Godfrey CM, Khalil H, McInerney P, Parker D, Soares CB. Guidance for conducting systematic scoping reviews. Int J Evid-Based Healthc. 2015;13(3):141-6.

8. Colquhoun HL, Levac D, O'Brien KK, Straus S, Tricco AC, Perrier L, et al. Scoping reviews: time for clarity in definition, methods, and reporting. J Clin Epidemiol. 2014;67(12):1291-4.

9. Lima K, Bernardino E. Nursing care in a hematopoietic stem cells transplantation unit. Texto Contexto Enferm. 2014;23(4):845-53.

10. Cruz FB, Ikeda AL, Rosa LM, Radunz V, Anders JC. Padronização dos procedimentos de enfermagem na infusão autogênica de célulastronco hematopoiéticas. Rev Enferm UERJ. 2017;25(0):e8057.

11. Figueiredo TW, Mercês NN, Silva LA, Machado CA. Protocolo de cuidados de enfermagem no dia zero do transplante de célulastronco hematopoéticas: construção coletiva. Texto Contexto Enferm. 2019;28:e20180010.

12. Rodrigues JA, Lacerda MR, Gomes IM, Paes MR, Ribeiro RP, Mercês NN. Research contributions for the Nursing care in pediatric transplantation of hematopoietic stem cells. Rev Pesqui Cuid Fundam Online. 2018;10(4):964-70.

13. Tormey CA, Snyder EL. Hematopoietic progenitor cell administration. In: Wingard JR, Gastineau DA, Leather HL, Snyder EL, Szczepiorkowski ZM, editors. Hematopoietic stem cell transplantation: a handbook for clinicians. Bethesda: American Association of Blood Banks; 2015. p. $191-9$.

14. Young LK, Mansfield B, Mandoza J. Nursing care of adult hematopoietic stem cell transplant patients and families in the intensive care unit: an evidence-based review. Crit Care Nurs Clin North Am. 2017;29(3):34152.

15. Castro EA, Andrade AM, Santos KB, Soares TC, Esterci LT. Self-care after autologous bone marrow transplantation within the nursing care process. Rev RENE. 2012;13(5):1152-62.

16. Castanho LC, Silveira RC, Braga FT, Canini SR, Reis PE, Voltarelli JC. Motivo de retirada do cateter de Hickman em pacientes submetidos ao transplante de células-tronco hematopoiéticas. Acta Paul Enferm. 2011;24(2):244-8.

17. Pontes L, Silva SR, Lima AP, Sandri LC, Batistela AP, Danski MT. Incidentes relacionados ao cateter de Hickman®: identificação de dano. Rev Bras Enferm. 2018;71(4):1915-20.

18. Pereira JZ, Braga FT, Garbin LM, Castanho LC, Silveira RC. Permanence of Hickman Catheter in patients undergoing allogeneic hematopoietic stem cell transplantation: retrospective study. Rev Bras Cancerol. 2013;59(4):539-46.

19. Gavin NC, Webster J, Chan RJ, Rickard CM. Frequency of dressing changes for central venous access devices on catheter-related infections. Cochrane Database Syst Rev. 2016;2:CD009213.

20. Rodrigues HF, Garbin LM, Castanho LE, Simões BP, Curcioli AC, Silveira RC. Hickman catheters in hematopoietic stem cell transplantation: surgical implantation, removal and nursing care. Rev Enferm UERJ. 2015;23(3):304-9.

21. Biagioli V, Piredda M, Annibali 0, Tirindelli MC, Pignatelli A, Marchesi $\mathrm{F}$, et al. Development and initial validation of a questionnaire to assess patients' perception of protective isolation following haematopoietic stem cell transplantation. Eur J Cancer Care (Engl). 2019;28(2):e12955. 
22. Vokurka S, Bystrická E, Svoboda T, Škoda Gorican IK, Sever M, Mazur $\mathrm{E}$, et al. The availability of HEPA-filtered rooms and the incidence of pneumonia in patients after haematopoietic stem cell transplantation (HSCT): results from a prospective, multicentre, eastern European study. J Clin Nurs. 2014;23(11-12):1648-52.

23. Siefker S, Vogelsang N. Nursing interventions for the patient experiencing mucositis. Biol Blood Marrow Transplant. 2018;24(3):S111-2.

24. Santos BN, Oliveira MC, Braga FT, Margatho AS, Esparrachiari LC, Silveira RC. Local cutaneous effects associated with chlorhexidineimpregnated gel dressing in hematopoietic stem cell transplantation patients. Open J Nurs. 2018;8(2):115-29.
25. Neumann J. Nursing challenges caring for bone marrow transplantation patients with graft versus host disease. Hematol Oncol Stem Cell Ther. 2017;10(4):192-4.

26. Mazza VA, Souza C, Estevão AR, Guimarães SL, Mercês NN. Vivência de famílias de crianças e adolescentes submetidos ao transplante de células-tronco hematopoéticas. Rev Eletr Enf. 2016;18:e1193.

27. Gutiérrez MG, Morais SC. Sistematização da Assistência de Enfermagem e a formação da identidade profissional. Rev Bras Enferm. 2017;70(2):436-41.

28. Morrison CF, Pai AL, Martsolf D. Facilitators and barriers to selfmanagementfor adolescents and young adults following a hematopoietic stem cell transplant. J Pediatr Oncol Nurs. 2018;35(1):36-42. 